\title{
Second-order classical conditioning of meaning in the Staats format
}

\author{
GARY MORAN \\ Florida International University, Miami, Florida 33199
}

\begin{abstract}
Five nonsense syllables were paired 18 times each with meaningful words. Two syllables $\left(C_{1}\right)$ were paired systematically with words (UCS) of either positive or negative evaluative connotation, and the remaining syllables were paired with words without systematic evaluative connotation. Postexperimental ratings on semantic differential scales indicated that the syllable paired with positive words was evaluated more positively than the syllable paired with negative words $(p<.001)$. This replicates Staats and Staats' well known finding. Part 2 of the experiment had two conditions. In Condition 1, the positive $\mathrm{CS}_{1}$ from Part 1 was paired with one neutral $\mathbf{C S}_{2}$, and the negative $\mathbf{C S}_{1}$ was paired with another $\mathbf{C S}_{2}$. In Condition 2, the pairings of the positive and negative $\mathrm{CS}_{1} \mathrm{~s}$ were reversed for the $\mathrm{CS}_{2} \mathrm{~s}$. Three noncritical pairs of nonsense syllables were also presented. A significant interaction $(p<.05)$ in the rating of $\mathrm{CS}_{2} \mathrm{~s}$ in the different conditions indicated that they had acquired the connotative meaning associated with $\mathrm{CS}_{1}$ s. Results support the phenomenon of second-order classical conditioning of syllables.
\end{abstract}

Staats and Staats (1957), noting Razran's (1955) observation that no American laboratory had as of that date reported successful second-order classical conditioning, presented an interesting and seminal experiment purporting to demonstrate second-order classical conditioning of meaning. In the Staats and Staats format, nonsense syllables are paired with meaningful words and are shown to acquire the connotative meaning of those words. Staats and Staats assert that meaningful words are ipso facto conditioned stimuli. On this logic, they have demonstrated second-rather than first-order conditioning. Arguably, meaningful words operate more like primary reinforcers than like conditioned stimuli.

Page (1969) presented evidence that the results in the Staats and Staats (1957) study might be attributed to demand characteristics operating on the subjects. In a persuasive rebuttal, Staats (1969) argued that consideration of additional findings suggests that the classical conditioning explanation is the more encompassing and parsimonious. He suggested, for example, that the CS for an attitude response should itself come to have reinforcing properties. Staats implied that an experiment by Finley and Staats (1967) supported the assertion. Regrettably, however, Finley and Staats demonstrated only that meaningful words (the UCS in Staats \& Staats, 1957) reinforced motor responses much as they reinforced nonsense syllables. What is needed is a demonstration that the original CS (the nonsense syllable) can reinforce new responses.

The current study will attempt to support the Staats and Staats (1957) contention that second-order classical conditioning can be demonstrated, by extending their

Reprint requests should be addressed to Gary Moran, Department of Psychology, Florida International University, Miami, Florida 33199. original experimental design. After nonsense syllables have been paired with meaningful words, these syllables will in turn be paired with new nonsense syllables. The new nonsense syllables $\left(\mathrm{CS}_{2} \mathrm{~s}\right)$ should acquire the meaning of the original nonsense syllables $\left(\mathrm{CS}_{1} \mathrm{~s}\right)$ with which they are paired.

\section{METHOD}

Subjects were informed that the experiment had two parts. The first part was concerned ostensibly with how the learning of nonsense syllables and the learning of meaningful words takes place together. The 56 subjects were shown $903 \times 5$ in. cards, each containing a nonsense syllable followed by a meaningful word. Each of the nonsense syllables, YOF, XEH, WUH, GIW, and QUG, appeared with a different meaningful word 18 times. YOF was always paired with a word having a positive evaluative connotation, and XEH was paired with a word having a negative evaluative connotation. The remaining syllables were paired with words without systematic connotative significance. The list, with one deletion, was adapted from Staats and Staats (1957). Each card was exposed for $1 \mathrm{sec}$ and the experimenter spelled the syllable, pronounced the word, and had the subject follow in like manner.

The second part of the experiment consisted of exposing 90 cards for $1 \mathrm{sec}$ each and asking the subject to spell out each of the two nonsense syllables after the experimenter had done the same. In Condition 1,32 subjects were exposed 18 times to each of the syllable pairs CEF-YOF and DAX-XEH and to three noncritical pairs, WUB-GEX, JID-LAJ, and MYV-QUG. In Condition 2, 24 subjects were exposed 18 times to each of the syllable pairs CEF-XEH and DAX-YOF and to the noncritical pairs.

At this point, the subject was informed that prior to seeing how much he/she had learned, it would be necessary to find out how he/she felt about the nonsense syllables. The subject was given separate sheets containing eight 7 -point semantic differential scales for each syllable in the study. The order in which each syllable was rated was counterbalanced. Each syllable was rated between 2 (low) and 14 for the connotative dimensions (positive) evaluation (pleasant-unpleasant, good-bad), activity (lively-still, active-passive), potency (strong-weak, tough-tender), 
and stability (tamed-untamed, rational-emotional). In the instance of each connotative dimension, the two scales were leftright counterbalanced for the order of presenting the positive evaluative, active, and so on, word.

\section{RESULTS}

In Part 1 of the experiment, YOF was paired systematically with words of common positive evaluative connotation and $\mathrm{XEH}$ was paired with words of negative connotation. YOF (10.0) was rated significantly $(F=$ $48.9, \mathrm{p}<.001)$ more positively than XEH (6.0).

Part 2 of the experiment had two conditions. In Condition 1, the prior CS from Part 1 (YOF) was paired with the new CS (CEF) and the prior CS (XEH) with the new CS (DAX). In Condition 2, YOF was paired with DAX. and XEH with CEF. The interaction $(p<.05)$ reported in Table 1 indicates that in Condition 1 , CEF (9.72) was evaluated more positively than DAX (7.75), whereas in Condition 2, DAX (9.08) was evaluated more positively than CEF (8.63). These two syllables did not differ when rated on either the activity or the stability dimension. Inexplicably, DAX was rated more potent $(p<.005)$ in both conditions of Part 2 of the experiment. This would not seem to affect interpretation of the interaction term in the ANOVA for evaluation.

\section{DISCUSSION}

Staats and Staats' (1957) often replicated (Page, 1969; Staats, 1969) finding that a nonsense syllable acquires the connotative meaning of evaluative words with which it has been paired was replicated again in this study. Staats and Staats suggest that this phenomenon itself represents second-order classical conditioning of meaning. Whether meaningful words are to be considered primary or secondary reinforcers for adult humans may be a matter of taste (i.e., theoretical persuasion). A CS is
Table 1

Summary of Analysis of Variance for "Evaluation" Ratings of CEF and DAX

\begin{tabular}{lrrl}
\hline \multicolumn{1}{c}{ Source } & df & MS & \multicolumn{1}{c}{ F } \\
\hline CEF & 1 & .39 & \\
DAX & 1 & 15.64 & 1.97 \\
CEF by DAX & 1 & 40.39 & $5.08^{*}$ \\
ERROR & 108 & 7.94 & \\
\hline
\end{tabular}

${ }^{*} p<.05$.

said to have some, but not all, of the properties of a UCS. There is abundant evidence (Staats, 1969) that meaningful words reinforce behavior in exactly the same way as do other primary reinforcers. On this logic, an additional step is required to demonstrate the second-order conditioning of meaning. The current finding that a nonsense syllable that has acquired reinforcing properties by its contiguous presentation with meaningful words can in turn imbue a new syllable with its acquired meaning would seem a less conjectural example of second-order conditioning.

\section{REFERENCES}

Finley, J. R., \& StaAts, A. W. Evaluative meaning words as reinforcing stimuli. Journal of Verbal Learning and Verbal Behavior, 1967, 6, 193-197.

PAGE, M. M. Social psychology of a classical conditioning of attitudes experiment. Journal of Personality and Social Psychology, 1969, 11, 177-186.

Razran, G. H. S. A note on second-order conditioning and secondary reinforcement. Psychological Review, 1955, 62, 327-332.

StaAts, A. W. Experimental demand characteristics and the classical conditioning of attitudes. Journal of Personality and Social Psychology, 1969, 11, 187-192.

Stants, C. K., \& StaAts, A. W. Meaning established by classical conditioning. Journal of Experimental Psychology, 1957, 54, 74-80.

(Received for publication October 17, 1981.) 